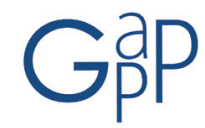

GESTIÓN Y ANÁLISIS DE POLÍTICAS PÚBLICAS, Nueva Época, nº 14 julio-diciembre 2015 ISSN: 1989-8991

DOI: http://dx.doi.org/10.24965/gapp.voi14.10291

\title{
Economía social y empresa social. Análisis del marco conceptual y jurídico en España ${ }^{1}$
}

\author{
María Alvarado Riquelme \\ Universidad Rey Juan Carlos \\ maria.alvarado@uric.es \\ María Auxiliadora de Vicente Oliva \\ Universidad Rey Juan Carlos \\ maria.devicente@uric.es \\ Ricardo García Vegas \\ Universidad Rey Juan Carlos \\ ricardo.garcia.vegas@uric.es \\ Alejandro Agafonow \\ Monash University (Australia) \\ alejandro.agafonow@monash.edu
}

Resumen

Las empresas sociales han tenido un importante desarrollo en la producción de bienes y servicios que complementan la labor del Estado y el mercado a la hora de satisfacer las necesidades de la población en áreas tan sensibles como: la salud, la educación, la producción de alimentos, el apoyo a la tercera edad etc. Nuestra investigación pretende modelizar los patrones de negocio de las empresas sociales e identificar las variables clave que incentivan la innovación social con el fin de definir nuevos mecanismos de gobernanza en la producción de bienes y servicios públicos.

Palabras clave

Economía social, empresa social, innovación social.

\section{Social economy and social enterprise. Conceptual and legal framework analysis in Spain}

\section{Abstract}

Social enterprises have had an important development in the production of goods and services that complement the state and the market in meeting the needs of the population in sensitive areas such as health, education, food production, support for the elderly etc. Our research aims to model the business patterns of social enterprises and to identify key variables that make social innovation possible, in an attempt to understand new governance mechanisms in the production of public goods and services.

Keywords

Social Economy, Social Enterprise, Social Innovation.

1 Este artículo se enmarca en un proyecto de investigación financiado por el Instituto Nacional de Administración Pública de España (INAP), cuyo objetivo general es "diseñar un modelo integrado para la identificación, medición y valoración de las variables que, con mayor potencial estratégico, definen el modelo de negocio adoptado en las empresas sociales e incentivan el desarrollo de la innovación social”. El contenido de este artículo es el resultado de la fase inicial de la investigación, a través de la cual se ha definido el marco conceptual y jurídico de la empresa social en España con el fin de delimitar las siguientes fases de la investigación. 


\section{INTRODUCCIÓN}

En las últimas tres décadas se ha producido una fuerte expansión de la economía social, un sector situado entre el sector público y el privado que ha recibido otras denominaciones como tercer sector (Chaves, 2007; Argudo, 2002; Sajardo y Chaves, 1999; Tomas, 1997), non-profit sector o sector no lucrativo (Hwang and Powell, 2009; Sinitsyn and Weisbrod, 2008; Hansmann, 1980; Argudo, 2002; Chaves, 2007), economía solidaria (CIRIECInternational, 2011, Chaves 2007), sector cooperativo (Chaves, 2007), sector de organizaciones voluntarias (Kramer, 1981; Chaves, 2007) y sector emergente (Argudo, 2002).

El término de "economía social" empieza a ser usado en el siglo xx para referirse al estudio de una forma específica de organizar el uso de factores de producción, esto es las cooperativas de producción, y más ampliamente a sus implicaciones sociales. A finales del xx la economía social ha girado hacia el estudio de modelos híbridos de empresas y su contribución a un crecimiento económico más inclusivo, como las empresas sociales y las corporaciones de beneficio público.

La importancia del estudio de la economía social y específicamente de las empresas sociales radica en el hecho de que actualmente en Europa emplea a más de 14 millones de personas (Monzón y Chaves, 2012). En España está constituida por casi 50.000 empresas, que generan 2.5 millones de empleo y una facturación que ronda los 115.000 millones de euros (10\% del PIB Español). Estos datos la convierten en una realidad económica significativa y, por tanto, indiscutible.

Además, algunos de sus elementos identitarios se han traducido en claros argumentos económicos y sociales a favor de este tipo de realidad empresarial. Las empresas sociales son empresas competitivas, generadoras de empleo, que resuelven crisis sectoriales o territoriales gracias a su capacidad colectiva de reaccionar frente a los problemas sociales. Son empresas que se crean en el territorio, desde los problemas surgidos en él y responde a éstos ofreciendo soluciones positivas. Potencian el espíritu emprendedor de las personas, la participación en la gestión y contribuyen a la construcción de una sociedad más equitativa, a la integración de personas con discapacidad o en riesgo de exclusión social, de valores democráticos y de riqueza colectiva.

Las empresas sociales han tenido un importante desarrollo en la producción de bienes y servicios que complementan la labor del Estado y el mercado a la hora de satisfacer las necesidades de la población en áreas tan sensibles como: la salud, la educación, la producción de alimentos, el apoyo a la tercera edad etc. Además de la importancia que tienen en la dinámica de la economía, las empresas sociales se han convertido en centros de innovación social, en la medida en que estos bienes y servicios suponen una importante transformación de las relaciones humanas y del entorno social.

Para ello, han adoptado nuevos modelos de negocio y han promovido valores que las distinguen de otras organizaciones como las empresas privadas o las organizaciones no gubernamentales. En esta línea, el objetivo de este trabajo es aportar un marco conceptual sobre las empresas sociales que facilite el diseño de un modelo integrado para la identificación, medición y valoración de las variables que, con mayor potencial estratégico, explican la innovación social. De manera, que los productos obtenidos contribuyan a la mejora de las organizaciones públicas, de sus políticas y de la producción de bienes y servicios públicos.

Los aprendizajes derivados del funcionamiento de las empresas sociales pueden transferirse con éxito al sector público. La posibilidad de estudiar a profundidad los modelos de negocio de las empresas sociales e identificar las variables clave que incentivan la innovación social, representa una valiosa contribución para definir nuevos mecanismos de gobernanza en la producción de bienes y servicios públicos. Este aporte tiene un especial interés cuando se habla de sinergias e intercambio de recursos estratégicos en el marco de la colaboración público-privada.

Hemos estructurado el artículo en ocho secciones en las que analizamos el concepto de empresa social (sección 2), la tipología de las empresas sociales (sección 3), los enfoques para el estudio de las empresas sociales (sección 4), el marco jurídico español de la economía social y las empresas sociales (sección 5) y la innovación social en este tipo de empresas (sección 6). En la sección 7 proponemos un sistema de variables para el estudio de la innovación en la empresa social y, por último, ofrecemos nuestras conclusiones (sección 8).

\section{EL CONCEPTO DE EMPRESA SOCIAL}

La investigación sobre empresas sociales tiene su origen en el interés generado por la transición que el tercer sector ha experimentado desde una vocación en su origen militante y caritativo, hacia estrategias de naturaleza más comercial. Esta transición motivó la diferenciación entre organización sin fines de lucro caritativas y organización sin fines de lucro comerciales sugerida por Hansmann (1980), siendo éstas últimas las conocidas hoy como empresas sociales, social businesses o en Estados Unidos, corporaciones de beneficio público. El interés por 
el trabajo de estas organizaciones se fue incrementando a medida que se consolidaba su papel en la producción de bienes y servicios para la comunidad, de forma complementaria al sector público, con su colaboración o sin ella.

Es conocida la importancia que tiene la empresa social, entendida como "nuevas ideas que resuelven los problemas sociales" (Buckland y Murillo, 2013), en lo que respecta a la redistribución de la renta o de los bienes en los que ésta se invierte (Fundació Banc dels Aliments de Barcelona), en las formas de financiación para que éstas contribuyan y no obstaculicen la labor social de las entidades (AVAAZ, Behavioural Insights Team), en el intercambio de bienes e ideas (Redes de intercambio de Barcelona, Red Ropa Amiga), en el cuidado del medioambiente, la reeducación política, empresarial y social para lograr un mundo sostenible o la educación inclusiva. En definitiva para producir bienes y servicios que respondan a problemas complejas y satisfagan de manera complementaria las necesidades humanas.

Las investigaciones sobre las organizaciones sin fines de lucro comerciales se remontan a la segunda mitad del siglo Xx en Estados Unidos, donde su aparición tuvo lugar en los sectores de educación, servicios personales, salud y artes escénicas. Las principales teorías al respecto se empezaron a elaborar aplicando generalmente teorías bien contrastadas en otros ámbitos como la teoría de la agencia, la teoría institucional, la teoría del valor añadido, la teoría del comportamiento colectivo y la teoría de la complejidad.

La literatura generada en estos años se ha preocupado por clarificar el alcance del concepto de empresa social e identificar sus elementos diferenciadores con respecto a otras formas de organización social y económica que participan en la producción de bienes y servicios públicos y privados. Las primeras investigaciones sobre este último tema se han centrado en establecer estas diferencias desde una perspectiva económica, fundamentalmente en lo relativo a la generación y captura del valor económico, la sostenibilidad financiera de las empresas y el uso de los dividendos de su actividad productiva.

La evidencia sugiere como elemento clave de estos temas que las empresas sociales suelen tasar su producción a precios menores que las empresas con fines de lucro, usando los superávits, no con el propósito de distribuir dividendos (lo cual está legalmente prohibido en el tercer sector de muchos países), sino para expandir la producción más allá de lo que las empresas privadas consideran económicamente beneficioso. Así, los márgenes de beneficios se reducen en las empresas sociales con el objetivo de favorecer a consumidores desfavorecidos pero éstas también permanecerán atentas a la cobertura de los costes de producción para garantizar su sostenibilidad financiera.

Las investigaciones sobre las empresas sociales revelan que la conducción de los negocios busca mantener los precios del output producido tan bajos como sea posible, fomentando así el acceso a estos bienes y servicios por parte de la población desfavorecida. Al mismo tiempo, los precios son fijados lo suficientemente altos para proteger la sostenibilidad financiera de las empresas sociales, procurando cumplir con su restricción presupuestaria. Así, las empresas sociales fijan precios más bajos que sus pares con fines de lucro para maximizar output, en lugar de beneficio económico y su distribución a los accionistas en forma de dividendos. Esto en lo que concierne a evidencia en el ámbito del cálculo monetario y la contabilidad. Asimismo, se sugieren hipótesis sobre el aspecto psicológico y conductual. Los gerentes y administradores de las empresas sociales maximizarían su prestigio, estatus u otros beneficios no pecuniarios, lo que representa una alternativa egoísta a las restricciones que previenen la distribución de dividendos, aunque también hay espacio para hipótesis del altruismo en la literatura (Miller et al. 2012).

En Europa, las investigaciones sobre este tema tienen su hito en la década de 1990, cuando un proyecto financiado por la Unión Europea (UE) llevó a cabo una primera descripción de las entonces nacientes empresas sociales. Esta investigación se realizó en el $4 .^{\circ}$ programa marco de la UE y se tituló: “L'Émergence des Entreprises Sociales, réponse novatrice à l'exclusion Sociale en Europe”. También conocida como EMES. La investigación arrojó luz sobre las dificultades que las empresas sociales enfrentaban para conseguir financiación. Algunos de sus investigadores, como Borzaga and Solari (2001), concluyeron que las empresas sociales constituyen un modelo de negocio novel e híbrido que dificulta la labor de los inversionistas e instituciones financieras al evaluar la factibilidad de invertir en éstas. En una reciente actualización del estudio, EMES identificó algún progreso en los marcos legales europeos al abrir un espacio para una tratamiento especializado de las empresas sociales (Defourny and Nyssens, 2008).

Numerosas definiciones de empresa social y emprendimiento social han sido propuestas (p.ej. Austin, Stevenson, \& Wei-Skillern 2006; Bacq \& Janssen 2011; Dacin, Dacin, \& Matear 2010; Defourny \& Nyssens 2006; Hoogendoorn, Pennings, \& Thurik 2010; OECD, 2010; Peredo \& McLean 2006; Short, Moss, \& Lumpkin 2009; Zahra, Gedajlovic, Neubaum, \& Shulman 2009). Por un lado, en un esfuerzo por diferenciar las empresas sociales de las empresas con fines lucro, una parte de la literatura ha enfatizado la no apropiación de márgenes de beneficio por parte de los dueños o accionistas de la empresa social. Tal como las organizaciones sin fines de lucro tradicionales, las empresas sociales adopta una "restricción de no distribución de beneficios" (Hansmann 1980; Hansmann 1996; Krashinsky 1986; Rose-ackerman 1996; Valentinov 2008; Weisbrod 1989). 
Esta restricción facilita la reinversión de los márgenes beneficio en la empresa misma, además de ofrecer una garantía a los consumidores de que la cantidad o calidad de la producción no será sacrificada para economizar con miras a enriquecer a los propietarios. Esta restricción de no distribución de márgenes de beneficio constituye un mecanismo que incrementa la confianza en las transacciones entre la empresa y los clientes, ya que la empresa social no tendría incentivos para tomar ventaja de la falta de información de los clientes sobre las características de la producción, que con frecuencia incluye bienes o servicios difíciles de evaluar por parte del consumidor.

Recientemente y en esta misma línea, Muhammad Yunus ha adoptado esta restricción llamándola una condición de no dividendo, es decir, no habría accionistas que reciban dividendos. Yunus sostiene que enriquecerse a costa de clientes pobres, a los que las empresas sociales dirigen su oferta, es inmoral y la no distribución de dividendos prevendría esto. Asimismo, Yunus define la empresa social como una empresa que debe impedir pérdidas financieras y ser económicamente sostenible. Por tanto, una empresa de no dividendo y no pérdida es la definición que emerge del trabajo de Yunus (Kickul et al. 2012; Yunus et al. 2010; Yunus \& Weber 2007; Yunus \& Weber 2010).

Aunque hay buenas razones para creer que entre el margen de beneficio y la calidad o cantidad de la oferta, es esta última la que es sacrificada cuando una empresa que distribuye dividendos se encuentra bajo presión de la competencia, hay quienes proponen que la apropiación de beneficios por parte de accionistas o dueños no rivaliza con la misión de una empresa social. Según esta perspectiva, las empresas sociales serían un tipo de empresa con fines de lucro socialmente responsable. La ventaja de mantener la captura y apropiación de valor (manifiesta en márgenes de beneficio) en las empresas sociales es que podría atraer más fácilmente financiación para incrementar el tamaño de la empresa, una debilidad que sufren las empresas sociales que no distribuyen dividendos (Dees 1998; Dees \& Anderson 2003; Drucker 1994; Martin \& Osberg 2007; Seelos \& Mair 2004).

Otra influyente definición de empresa social fue ofrecida por el EMES European Research Network, que ha desarrollado varios estudios con el apoyo financiero de la Comisión Europea. A partir de la constatación de que las empresas con fines de lucro también prestan atención a variables no solamente financieras, incluyendo la opinión de terceras partes interesadas y afectadas por el funcionamiento de la empresa, EMES ha desarrollado un modelo de empresa social que, además de salvaguardar la viabilidad financiera de la empresa, da voz y voto a terceras partes interesadas en el control de la empresa social. Esto implica un modelo de toma de decisiones cooperativo, que sin embargo distingue a las empresas sociales de las cooperativas de productores (Campi et al. 2006; Borzaga \& Tortia 2007).

La diferencia radica en que la empresa social EMES produce bienes y servicios ligados a un impacto social, también conocidos como servicios de interés económico general, algo a lo que no están obligadas ni las empresas socialmente responsables ni las cooperativas. Asimismo, una limitación de la apropiación de dividendos por parte de los dueños de la empresa social es puesta en práctica (Borzaga \& Defourny 2004; Borzaga \& Galera 2012; Defourny \& Nyssens 2006; Defourny \& Nyssens 2008). Esta "distribución de dividendos limitada" permitiría alcanzar el efecto conseguido en otros modelos anteriormente descritos, esto es una reinversión de parte de los márgenes de beneficio en la empresa, previniendo en menor medida los fallos de mercado que llevarían a las empresas con fines de lucro a abusar de información imperfecta en manos de los clientes para reducir calidad o cantidad.

Otro modelo que merece ser destacado, es el seguido por Social Enterprise UK (2012). De forma similar al modelo EMES, se impide la venta de un porcentaje mayor a $49 \%$ de acciones de la empresa social a accionistas externos, poniendo así un límite a la distribución de dividendos. La participación accionaria que permite el control de la empresa social debe estar, de acuerdo a Social Enterprise UK (2012), al servicio de la misión social reflejada en los estatutos de la empresa. Tal vez el aspecto más distintivo de este modelo de empresa social, es que no se limita a un modelo comercial. Ya que una empresa social para alcanzar estatus legal debe obtener en un máximo de dos años más del $50 \%$ de sus ingresos provenientes de actividades comerciales, hay espacio para subsidios y donaciones, aspecto que caracteriza a organizaciones tradicionales del tercer sector.

Basados en esta revisión de la literatura, una definición operativa de empresa social diría que ésta es una empresa cuya misión se orienta a la atención de problemas sociales y la satisfacción de necesidades de la población, mediante la provisión de bienes o servicios de interés económico general. Son entidades financieramente sostenibles y sus márgenes de beneficios se reinvierten íntegramente o en su mayoría en la producción de bienes o servicios destinados a una población desfavorecida.

\subsection{ELEMENTOS DIFERENCIADORES DE LAS EMPRESAS SOCIALES}

\subsubsection{Frente a las empresas privadas}

Este es uno de los elementos más controvertido y menos sistemáticamente abordado en la literatura sobre empresas sociales. Ya que estas deben ser sostenibles financieramente, en qué medida las empresas sociales se distinguen de 
las empresas con fines de lucro ha recibido un tratamiento poco riguroso. Lo que se desprende de los conceptos anteriormente señalados es que la diferencia radicaría, dependiendo de la definición adoptada, en tres elementos: misión social; cierta forma de toma de decisiones; y distribución limitada de dividendos o no distribución en absoluto.

En el caso de la misión social, es difícil ver cómo por sí sola sería suficiente para diferenciar a una empresa social. Puede decirse que las empresas con fines de lucro socialmente responsables también tienen una misión social, e incluso podemos encontrar algunas de estas últimas destinando parte de sus beneficios a causas sociales. Algo similar sucede con la toma de decisiones. Para empezar, una empresa social puede tener una toma de decisiones cooperativa o no, y tal característica puede conseguirse en empresas con fines de lucro cooperativas o no.

Quizá el elemento más distintivo se encuentre en la distribución limitada de dividendos o no distribución en lo absoluto, aunque también podemos conseguir esta característica en las llamadas empresas gacela, que son pequeñas y medianas empresas de alto crecimiento, donde los márgenes son reinvertidos para incrementar la escala de producción que sube la rentabilidad de la inversión.

Para prevenir esta confusión, Santos (2012) sostiene que mientras una empresa con fines de lucro satisface en creación de valor y maximiza en captura de valor (es decir la creación de valor se lleva hasta niveles meramente necesarios para atraer clientes, pero el valor añadido al producto es reducido para incrementar la captura de valor monetario expresada en dividendos), un emprendedor social haría lo opuesto: es decir, maximizar en creación de valor y satisfacer en captura de valor. La captura de valor en una empresa social se llevaría a cabo con el propósito de reinvertir este dinero en la empresa misma.

No obstante, Santos (2012) siguiendo a Simon (1959) usa el término de satisfacer (traducción de forma imprecisa del término compuesto "satificing", que combina "satisfy" y "suffice") para denotar un esfuerzo menos intenso que el de maximizar y así distinguir a una empresa que maximiza beneficios, de una empresa social que simplemente satisface en la producción de un margen de beneficio con un propósito social.

La diferencia entre satisfacer y maximizar en captura y creación de valor es todavía difícil de operacionalizar. Es por esto que Agafonow (2014) ha propuesto como alternativa la idea de "devolución de valor" para diferenciar a una empresa social de otras. La devolución de valor tendría una expresión económica clara, teniendo lugar cuando la empresa social produce más allá de lo necesario para maximizar la diferencia entre costes e ingresos, lo cual da el beneficio neto. Si la empresa social invierte más en calidad, cantidad o una combinación de ambas, el beneficio neto sería puesto al servicio de los clientes en lugar de los accionistas. Esto pasaría si la empresa social produce hasta donde el ingreso marginal iguala el coste total promedio, mientras que la fórmula de maximización de beneficios establece la igualación del ingreso marginal y el coste marginal. Así, una fórmula económica alternativa es creada siendo compatible con la sostenibilidad financiera.

La diferencia con organizaciones sin fines de lucro u ONGs en general, es más clara, quizá debido a que las empresas sociales han sido creadas en el seno del tercer sector como respuesta a las restricciones financieras de organizaciones que dependen de donaciones y subsidios para continuar operando. En búsqueda de menor dependencia financiera de filántropos y políticos, las empresas sociales surgen como un híbrido entre organizaciones con fines sociales y benéficos, y organizaciones de naturaleza comercial.

Por tanto, a diferencia de las ONGs que dependen de donaciones, incluso cuando venden productos con propósitos de transferir este dinero a una misión social, las empresas sociales se embarcan en la producción y comercialización de bienes y servicios cuya naturaleza está vinculada a un objetivo social. De ahí el término de "servicios de interés económico general" adoptada por la Comisión Europea (2013), también conocidos como servicios sociales y comunitarios, entre otros términos.

Así, las empresas sociales se diferencian de las ONGs por adoptar técnicas y procedimientos familiares en el sector con fines de lucro, dirigidos a la promoción de una misión social. En términos más rigurosos, las empresas sociales se dedican a "crear y devolver valor" a clientes desfavorecidos, mientras las ONGs redistribuyen recursos para beneficio de una población desfavorecida que no tienen el "derecho a elegir", tal como sí es el caso de un cliente propiamente dicho (Agafonow 2014).

\subsubsection{Frente a las empresas de la economía social}

Siguiendo a Sajardo y Chaves (1999) podemos identificar dos grandes áreas de interés en la economía social: (1) empresas de la economía social, centradas en la producción de bienes y servicios $\operatorname{con}^{2}$ o sin fines lucrativos 3

\footnotetext{
2 Cooperativas, mutuas y mutualidades, sociedades laborales y sociedades agrarias de transformación.

3 Fundaciones, asociaciones formalizadas con actividad económica, ciertas cooperativas y mutualidades, Cáritas, ONCE, Cruz Roja, Obras Sociales de Cajas de Ahorros, etc.
} 
(2) los agentes de la economía social comprometida4 (Tomas, 1997), formado por entidades sin actividad económica que acometen funciones de socialización, reivindicativas o políticas y que pueden revestir la forma de asociaciones de hecho y de asociaciones formalizadas sin actividad económica, con finalidades de encuentro (deportivas, de ocio, culturales, etc.), o políticas y/o de reivindicación (asociaciones profesionales, sindicatos, partidos políticos, etc.).

El concepto de empresa social es más restringido y está englobado en el de empresa de la economía social como vemos a través del siguiente cuadro en el que comparamos el contenido de la Ley 5/2011 en relación a las empresas de la economía social y las características comunes de la empresa social aportados por CESE (2012):

ILUSTRACIÓN 1. CARACTERÍSTICAS DE LA EMPRESA DE ECONOMÍA SOCIAL FRENTE A LA EMPRESA SOCIAL (FUENTE: ELABORACIÓN PROPIA)

\begin{tabular}{|c|c|c|}
\hline & Ley 5/2011 de Economía Social & CESE \\
\hline Filosofía & $\begin{array}{l}\text { - Persiguen bien el interés colectivo de } \\
\text { sus integrantes, bien el interés general } \\
\text { económico o social, o ambos. } \\
\text { - Promoción de la solidaridad, tanto inter- } \\
\text { na como con la sociedad, que favorezca } \\
\text { el compromiso con el desarrollo local, la } \\
\text { igualdad de oportunidades entre hom- } \\
\text { bres y mujeres, la cohesión social, la inser- } \\
\text { ción de personas en riesgo de exclusión } \\
\text { social, la generación de empleo estable y } \\
\text { de calidad, la conciliación de la vida perso- } \\
\text { nal, familiar y laboral y la sostenibilidad. }\end{array}$ & $\begin{array}{l}\text { Son agentes económicos productores } \\
\text { de bienes y servicios (frecuentemen- } \\
\text { te de interés general), a menudo con } \\
\text { una importante faceta de innovación } \\
\text { social. }\end{array}$ \\
\hline $\begin{array}{l}\text { Organización y modo } \\
\text { de propiedad }\end{array}$ & $\begin{array}{l}\text { - Primacía de las personas y del fin social } \\
\text { sobre el capital, que se concreta en una } \\
\text { gestión autónoma y transparente, de- } \\
\text { mocrática y participativa, que lleve a } \\
\text { priorizar la toma de decisiones más en } \\
\text { función de las personas, sus aportacio- } \\
\text { nes de trabajo y servicios prestados a la } \\
\text { entidad o en función del fin social, que } \\
\text { en sus aportaciones al capital social. } \\
\text { - Independencia sobre los poderes públi- } \\
\text { cos. }\end{array}$ & $\begin{array}{l}\text { - Su modo de organización o régi- } \\
\text { men de propiedad, basados en } \\
\text { principios democráticos o partici- } \\
\text { pativos u orientados a la justicia so- } \\
\text { cial, son reflejo de su misión. } \\
\text { - Actúan como entidades indepen- } \\
\text { dientes, con una importante faceta } \\
\text { de participación y codecisión (plan- } \\
\text { tilla, usuarios, accionistas), gober- } \\
\text { nanza y democracia (ya sea repre- } \\
\text { sentativa o abierta). } \\
\text { - A menudo proceden, o están aso- } \\
\text { ciadas con organizaciones de la so- } \\
\text { ciedad civil. }\end{array}$ \\
\hline Aplicación del resultado & $\begin{array}{l}\text { Aplicación de los resultados obtenidos de la } \\
\text { actividad económica en función del trabajo } \\
\text { aportado y servicio o actividad realizada por } \\
\text { las socias y socios o por sus miembros y, en } \\
\text { su caso, al fin social objeto de la entidad. }\end{array}$ & $\begin{array}{l}\text { Operar esencialmente sin ánimo de } \\
\text { lucro, reinvirtiendo principalmente } \\
\text { sus excedentes en lugar de distribuir- } \\
\text { los a sus accionistas privados o a sus } \\
\text { dueños. }\end{array}$ \\
\hline Formas jurídicas & $\begin{array}{l}\text { Las cooperativas, las mutualidades, } \\
\text { las fundaciones y las asociaciones que } \\
\text { lleven a cabo actividad económica, las } \\
\text { sociedades laborales, las empresas de } \\
\text { inserción, los centros especiales de } \\
\text { empleo, las cofradías de pescadores, las } \\
\text { sociedades agrarias de transformación } \\
\text { y las entidades singulares creadas por } \\
\text { normas específicas que se rijan por los } \\
\text { principios enumerados anteriormente. }\end{array}$ & $\begin{array}{l}\text { Múltiples formas jurídicas o modelos, } \\
\text { incluidas cooperativas, mutualidades, } \\
\text { asociaciones de voluntarios, } \\
\text { fundaciones, empresas con o sin } \\
\text { ánimo de lucro; combinando a } \\
\text { menudo distintas formas jurídicas } \\
\text { y, a veces, cambiando de forma en } \\
\text { función de sus necesidades. }\end{array}$ \\
\hline
\end{tabular}

4 Sajardo y Chaves (1999) los denominan «Sociedad civil», Monzón y Chaves (2012) «Subsector no de mercado». GESTIÓN Y ANÁLISIS DE POLÍTICAS PÚBLICAS, Nueva Época, n 89892015 ISSN: 1989-8991 - DOI: 10.24965/gapp.voi14.10291 
Como características diferenciadoras de la empresa social, frente al concepto de empresa de la economía social, podemos señalar que producen bienes y servicios de interés general con un fuerte componente de innovación social y operan esencialmente sin ánimo de lucro, reinvirtiendo principalmente sus excedentes en su proceso productivo.

\section{HACIA UNA TIPOLOGÍA DE EMPRESAS SOCIALES}

Es prematuro embarcarse en la propuesta de una tipología de empresas sociales. Actualmente existen proyectos internacionales que tienen como objetivo proponer una tipología, como es el caso del proyecto ICSEM coordinado por EMES. No obstante, podemos hacer referencia a una tipología general útil para diferenciar diferentes organizaciones del tercer sector. Esta tipología, distingue estas organizaciones a partir de sus fuentes de ingresos y la toma de decisiones dentro de la organización.

ILUSTRACIÓN 2. TIPOLOGÍA DE EMPRESAS SOCIALES (FUENTE: STEINBERG, 2006: 118).

\begin{tabular}{lll}
\hline & Mutual & Entrepreneurial \\
\hline Donative & Common cause & CARE \\
& National Audubon Society & March of Dimes \\
& Political clubs & Art museums \\
Commercial & American Automobile & National Geographic \\
& Assoc. & Society \\
& Consumers Union & Educational Testing \\
& Country clubs & Service \\
& & Hospitals \\
& & Nursing homes \\
\hline
\end{tabular}

Las empresas sociales se ubican en los dos cuadrantes inferiores, con una fuente de ingresos proveniente de actividades comerciales (comercial) y una toma de decisiones que puede estar en manos de un amplio grupo de actores (mutual) o simplemente un fundador (entrepreneurial). Esta clasificación es todavía muy general y habría que distinguir entre una comercialización ligada directamente a la misión y una comercialización como actividad ajena a la misión, que sin embargo intenta transferir recursos en apoyo de ésta. Esta última estrategia ha sido usada por ONGs durante largo tiempo y difícilmente puede ser considerada una empresa social ya los clientes no son una población necesariamente desfavorecida, y cada transacción busca maximizar beneficios para transferir recursos en apoyo de la misión avanzada por la ONG.

No obstante, para centrar la población objetivo de nuestra investigación tenemos que elegir, en base a los estudios, previos, en qué formas jurídicas vamos a centrarnos para enviar la encuesta y poder discernir cuáles son empresa social y cuáles quedarían fuera de esta consideración.

Las características de la empresa social coinciden aproximadamente con las de economía social productiva no lucrativa, por tanto, siguiendo a Sajardo y Chaves (1999), la población estaría formada por fundaciones, asociaciones formalizadas con actividad económica, ciertas cooperativas y mutualidades, Cáritas, ONCE, Cruz Roja, Obras Sociales de Cajas de Ahorros, empresas, sindicatos, bancos, partidos, parroquias, etc.

\section{ENFOQUES PARA EL ESTUDIO DE LAS EMPRESAS SOCIALES}

De las definiciones anteriores se desprende que los enfoques para el estudio de las empresas sociales son diversos. De manera muy general, los enfoques inductivos y deductivos están presentes y con frecuencia coexisten. Por ejemplo, el estudio de EMES European Research Network (Borzaga \& Defourny 2004), parte de una definición normativa de empresa social que posteriormente guiaría el trabajo de campo para la recolección de datos. Desde la perspectiva del emprendimiento social, el enfoque suele ser eminentemente inductivo, con observaciones sistemáticas de estudios de caso u observaciones transversales de numerosos emprendedores, intentando identificar características que se diferencian de otras formas de emprendimiento. También, la identificación de patrones comunes a grupos de emprendedores sociales es el objetivo de observaciones transversales.

Los enfoques deductivos han sido ampliamente usados en economía, particularmente la literatura sobre economía de "empresas sin fines de lucro", que comparten con las empresas sociales el objetivo de la sostenibilidad financiera a partir de la producción y venta de un bien o servicio. Así, este tipo de empresas se diferencian de las 
organizaciones sin fines de lucro con donaciones como principal fuente de sustento económico. Este enfoque es deductivo porque parte de ciertas bases conceptuales que con frecuencia han sido corroboradas por estudios empíricos, como los fallos de mercado, y procede a deducir implicaciones para el comportamiento de las empresas sociales.

Por ejemplo, a partir de la no apropiación de beneficios económicos postulada por varias definiciones de empresa social, se ha deducido que en ausencia de consumidores con información completa y conocimiento sobre las características del bien o servicio producido, las empresas sociales estarían menos inclinadas a explotar estos fallos de mercado a su favor y a expensas de los consumidores. Así, la no apropiación de beneficios permitiría incrementar la confianza que los consumidores ponen en estas empresas sociales (Ortmann 1996; Ortmann \& Schlesinger 2003; Ortmann \& Brhlikova 2010; Hansmann 1980; Hansmann 2003; Ben-Ner \& Van Hoomissen 1991; Steinberg \& Gray 1993; Steinberg 2006). Esto ha sido corroborado por estudios comparativos que revelan que las empresas con fines de lucro son más dadas a reducir la calidad de la producción tomando ventaja de la información y conocimiento imperfecto de los consumidores. Este es el caso de hogares de ancianos donde el uso de sedantes es más frecuente cuando este servicio es producido con fines de lucro (Weisbrod \& Schlesinger 1986). Asimismo, la duración de los tratamientos de diálisis son más cortos y la mortalidad más alta cuando el servicio es producido con fines de lucro que cuando es producido por empresas que no distribuyen beneficios (Brown \& Slivinski 2006).

Ambos enfoques, deductivo e inductivo, corren con riesgos. Desde un enfoque puramente inductivo, se corre el riesgo de identificar prácticas y estrategias de negocio que tienen poca probabilidad de sobrevivir a las presiones de la competencia proveniente de empresas con fines de lucro operando en los mismos mercados que las empresas sociales. Desde un enfoque puramente deductivo, se corre el riesgo de sesgar la teoría con prejuicios que son ajenos al fenómeno estudiado. Por ejemplo, el modelo cooperativo de toma de decisiones democrática forma parte de la definición normativa propuesta por EMES y es este punto de vista el que guía su trabajo de campo. No obstante, existen empresas que aun siendo financieramente sostenibles con una fuente de ingresos que deriva de la comercialización de un bien o servicio, cuya producción contribuye a paliar un problema social y cuyos beneficios económicos son reinvertidos en vez de ser apropiados por alguien, no tienen una toma de decisión democrática. En qué medida el modelo cooperativista de EMES excluye arbitrariamente cierto tipo de empresas sociales es algo que podría atribuirse a sus límites metodológicos.

Nosotros proponemos complementar estos enfoques con otro enfoque estadístico y de evaluación multicriterio. El acercamiento estadístico se basa en la realización y análisis de encuestas a las empresas sociales. El objetivo es describir y explicar cuáles son las características de las mismas así como los posibles patrones o perfiles (completando en este caso el enfoque inductivo y haciéndolo más riguroso). La evaluación multicriterio de las empresas nos permite un acercamiento de tipo constructivo al desempeño de la actividad empresarial en este sector. La construcción de los criterios sobre los que se llevará a cabo la evaluación será discutida y analizada con los expertos. Así como la modelización de las preferencias de cada criterio. Por último, aunque no menos importante, se procederá a establecer la importancia relativa que debe asignarse a cada criterio considerado. Creemos que esta combinación de enfoques clásicos (inductivo y deductivo) junto con otros más novedosos (estadístico y de evaluación multicriterio) nos permitirán caracterizar y explicar la empresa social en nuestro país.

\section{MARCO JURÍDICO ESPAÑOL DE LA ECONOMÍA SOCIAL Y LAS EMPRESAS SOCIALES}

El marco jurídico de la Economía Social española (delimitado por la Ley 5/2011, de 29 de marzo, de Economía Social) se centra en las empresas de economía social, así los artículos 2 y 4 de esta ley acotan el concepto de economía social como el conjunto de las actividades económicas y empresariales, que en el ámbito privado llevan a cabo aquellas entidades que, de conformidad con los siguientes principios:

- Primacía de las personas y del fin social sobre el capital, que se concreta en una gestión autónoma y transparente, democrática y participativa, que lleve a priorizar la toma de decisiones más en función de las personas, sus aportaciones de trabajo y servicios prestados a la entidad o en función del fin social, que en sus aportaciones al capital social.

- Aplicación de los resultados obtenidos de la actividad económica en función del trabajo aportado y servicio o actividad realizada por las socias y socios o por sus miembros y, en su caso, al fin social objeto de la entidad.

- Promoción de la solidaridad, tanto interna como con la sociedad, que favorezca el compromiso con el desarrollo local, la igualdad de oportunidades entre hombres y mujeres, la cohesión social, la inserción de personas en riesgo de exclusión social, la generación de empleo estable y de calidad, la conciliación de la vida personal, familiar y laboral y la sostenibilidad. 
- Independencia sobre los poderes públicos.

- Persiguen bien el interés colectivo de sus integrantes, bien el interés general económico o social, o ambos.

Por tanto, forman parte de la economía social (Ley 5/2011, art. 5), las cooperativas, las mutualidades, las fundaciones y las asociaciones que lleven a cabo actividad económica, las sociedades laborales, las empresas de inserción, los centros especiales de empleo, las cofradías de pescadores, las sociedades agrarias de transformación y las entidades singulares creadas por normas específicas que se rijan por los principios enumerados anteriormente.

Como hemos analizado previamente, la definición de economía social en nuestro ordenamiento jurídico está centrada en el sector productivo pero su alcance es más amplio que el de la empresa social que tendría una vocación no lucrativa en el sentido de priorizar sus objetivos sociales a la consecución del beneficio, pero sin renunciar a éste que se reinvertirá fundamentalmente en los fines sociales.

Del colectivo analizado de empresas sociales en España, nuestra investigación está centrada en la población formada por empresas de inserción social y centros especiales de empleo, incorporados, directa, o indirectamente en la base de datos de CEPES. El motivo para la elección de este tipo de empresas es su configuración jurídica. Las normativas que las regulan (Ley 44, 2007; RD 2273/1985) les confieren las características propias de una empresa social (de forma taxativa en el caso de las empresas de inserción mientras que en el caso de los centros especiales de empleo podemos encontrar también entidades sin ánimo de lucro) tanto por su objetivo (la integración y formación sociolaboral de personas en situación de exclusión social o minusválidos como tránsito al empleo ordinario); como por su forma jurídica (sociedades mercantiles o cooperativas -empresas de inserción- y empresas públicas o privadas con ánimo o sin ánimo de lucro -centros especiales de empleo-); por sus fuentes de financiación (a través de la realización de actividades económicas de producción de bienes y servicios) y por el destino dado a sus beneficios (deben aplicar, al menos, el ochenta por ciento de los resultados del ejercicio a la mejora o ampliación de sus estructuras productivas y de inserción -empresas de inserción-y la totalidad o parte del mismo en el caso de los centros especiales de empleo).

\section{EMPRESAS SOCIALES E INNOVACIÓN SOCIAL}

Un elemento que no debe perderse de vista es que muchas empresas sociales han adoptado modelos novedosos de negocio para asegurar el cumplimiento de los objetivos para las cuales fueron creadas. De manera que las teorías tradicionalmente utilizadas para describir a las empresas privadas se encuentran ahora en una interesante fase de revisión para ajustarse a las características propias de las empresas sociales.

Las empresas sociales se han convertido en importantes espacios para la innovación social, al producir bienes y servicios que han traído consigo una sustancial mejora en la forma cómo se atienden las demandas de la población. El concepto de innovación social hace referencia al desarrollo de productos o procesos novedosos que, estando orientados a la resolución de los problemas de las personas y la satisfacción de sus necesidades, suponen una mejora de las condiciones anteriores, así como una transformación del entorno social y de las relaciones humanas.

A partir de esta definición es posible establecer tres elementos diferenciadores de la innovación social con respecto a otros procesos innovadores que se puedan desarrollar en el ámbito empresarial:

- El objeto de la innovación social es responder a las necesidades y los problemas que afectan a la población, independientemente de la escala territorial donde se desarrollen, así como aportar soluciones novedosas frente a las alternativas disponibles.

- La innovación es el resultado de nuevos modelos de gobernanza que se sustenta en la transformación de las relaciones sociales. En la adopción de modelos colaborativos que promueven el intercambio de información y de conocimiento entre una multiplicidad de actores que intervienen en el hecho social.

- El fin último de la innovación social no es rentabilizar una inversión o generar valor económico para sus promotores, se trata de generar valor social. Los bienes y servicios deben propiciar el cambio y repercutir positivamente en la calidad de vida de las personas.

Para establecer una relación clara entre innovación social y empresas sociales en la literatura es usual traer a colación el ejemplo del Grameen Bank. Una empresa social exitosa que ha hecho de las microfinanzas una potente herramienta de lucha contra la pobreza, al promover (mediante el acceso al crédito) la participación de los grupos más vulnerables de la población en la dinámica económica. En España, se reconoce el trabajo de Moltacte, una empresa social que nació en 2006 con el objetivo de brindarles a las personas con trastornos mentales severos una oportunidad para que se desarrollen laboral y personalmente. 
Otra empresa como Catering Solidario se conectan con diversas organizaciones no gubernamentales para generar redes de apoyo que ofrece oportunidades de empleo a mujeres víctimas del maltrato machista y promueve productos que participan en el movimiento del comercio justo. En todos los casos reseñados, las empresas sociales han introducido elementos novedosos en la manera cómo producen bienes y servicios, han orientado su trabajo a la atención de problemas sociales de alta complejidad y han generado un importante impacto en la vida de las personas. En definitiva, se han convertido en organizaciones que innovan socialmente.

\section{SISTEMA DE VARIABLES PARA EL ESTUDIO DE LA INNOVACIÓN SOCIAL}

La innovación ha sido un importante objeto de estudios en diversas disciplinas como la sociología, la antropología o la economía con una mayor atención a la innovación tecnológica u organizativa. Si bien estos conceptos se ha abordado de manera multidisciplinar con enfoques diversos y en algunos casos contrarios entre sí, la unidad de análisis preferida en las investigaciones son las organizaciones, sean estas públicas, privadas o sociales.

En los últimos 40 años han sido numerosos los estudios publicados que, a partir de la identificación de variables explicativas de la innovación en las organizaciones (desde la perspectiva de su adopción o difusión), han desarrollado sistemas de medición complejos que pueden trasladarse con facilidad a cualquier organización, así como adaptarse a sus objetivos y características definitorias (Baldridge \& Burnham, 1975). Este aspecto cobra especial relevancia, si se tiene en cuenta la escasa literatura donde se presenten investigaciones focalizadas en el estudio de estas variables en el caso de las empresas sociales, y su relación con la innovación social. De ahí que una pregunta de interés en los últimos años se refiera a las variables clave que explican la innovación social en las empresas sociales.

La revisión de la literatura nos ha permitido construir un sistema de variables con las siguientes características. La primera es su estructuración de las variables en torno a los tres niveles de análisis utilizados comúnmente en los trabajos de investigación sobre innovación y empresas privadas (Kimberly \& Evanisko, 1981, p. 690). El primer nivel de análisis incluye las variables vinculadas al entorno en el que operan las empresas sociales y las interacciones que se producen con otros actores (públicos, privados o sociales). El segundo nivel agrupa las variables relativas a las características internas de la organización (modelo de organización), como por ejemplo los recursos disponibles, su tamaño o la estructura organizativa adoptada. El tercer nivel, se centra en las personas y articula las variables que describen las características individuales de los miembros de la organización como la cualificación, las aptitudes y el ejercicio del liderazgo a la hora emprender iniciativas de cambio.

La segundo característica se refiere a la identificación de las consecuencias asociadas a las variables seleccionadas (positivas y negativas) y su categorización. La idea central es que las variables tienen un impacto en el funcionamiento de las organizaciones que puede ser positivo o negativo con respecto a la innovación. Las consecuencias positivas son cualidades de las variables que facilitan la innovación en las empresas y por el contrario, las consecuencias negativas son condiciones adversas para su desarrollo. En este caso, el sistema de variables que proponemos se orienta a la descripción y el análisis de las variables desde sus atributos positivos. Son numerosas las investigaciones que se centran en las barreras de la innovación, dejando de lado el estudio detallado de sus facilitadores. Para ello, se ha tenido en cuenta el resultado de diversas investigaciones sobre la innovación en las empresas privadas, por lo que el reto estará en conocer su validez en el caso de las empresas sociales (Baldridge \& Burnham, 1975; Damanpour, 1996; Kimberly \& Evanisko, 1981; Subramanian \& Nilakanta, 1996; Teece, 1998).

\subsection{Entorno}

Los enfoques sistémico y de contingencia que se han desarrollado en el ámbito de la teoría de la organización otorgan un papel relevante al entorno a la hora de explicar la innovación en las organizaciones. Su importancia es crucial para el estudio de las empresas sociales si se tienen en cuenta que éstas deben interactuar con múltiples actores, funcionar en contextos caracterizados por alta incertidumbre y enfrentar situaciones de riesgo vinculados a la dinámica económica, política, social etc. del contexto en el que desempeñan sus tareas.

Relacionadas con el entorno se han identificado variables de carácter genérico, específico y vinculado con las redes estratégicas.

\subsubsection{Genéricas}

Las variables genéricas incluyen los factores económicos, sociales, culturales, político-institucionales o el avance de la sociedad de la información (Morales, 2004, p. 218). Se trata de factores externos a la organización, sobre los cuales ésta tiene un limitado poder de influencia, pero su desarrollo incide en el funcionamiento o 
rendimiento de las empresas. El impacto de estas variables pone a prueba las capacidades de la organización para desarrollar sus tareas y aplicar herramientas eficaces a la hora de predecir, comprender, enfrentar y reaccionar rápidamente ante los cambios que le afectan (Mintzberg, 1990, p. 310).

Con respecto a las variables genéricas hay dos variables clave de especial interés: el marco normativo e institucional y el tamaño de las ciudades donde se encuentran enclavadas las empresas sociales. El marco normativo e institucional hace referencia a las leyes o reglas que afectan las actividades desarrolladas por las empresas sociales, mediante la definición de una serie de incentivos y desincentivos de actuación en pro de determinados objetivos o criterios colectivos.

Se entiende que un marco normativo flexible que además contemple incentivos para la inversión, favorece el cambio y fomenta la generación de procedimientos o productos novedosos en las organizaciones. Por el contrario, se ha planteado en la literatura que un marco normativo rígido, con excesivas reglas burocráticas o escasa claridad en la regulación del sector económico-comercial donde intervienen las organizaciones, afecta su capacidad para promover procesos sostenibles de innovación. Además, la inexistencia o insuficiencia de incentivos institucionales que promuevan la inversión de recursos (públicos o privados) para el impulso de la innovación, afectaría las capacidades reales de las empresas sociales para desarrollar nuevos proyectos al ver limitado su acceso a las fuentes de financiación.

La segunda variable es el tamaño de las ciudades. Las ciudades son los principales centros de innovación y generación de conocimiento. Son espacios que favorecen el surgimiento de nuevos productos, servicios, ideas y en general, nuevas formas de hacer las cosas.

Las grandes ciudades brindan oportunidades de aprendizaje a sus habitantes, gracias al cúmulo de interacciones diarias que se producen en su territorio. Son interacciones de carácter social, académica o empresarial que, con distinta intensidad, se extienden a lo largo del territorio incentivando la innovación entre las empresas y los propios ciudadanos. Como establece Johnson (2011: 20) con una regla de la cuarta potencia positiva ha quedado demostrado que a medida que las ciudades crecen su capacidad innovadora es cada vez mayor. De tal forma que, por ejemplo, una ciudad 10 veces más grande que su vecina termina siendo 17 veces más innovadora.

\subsubsection{Específicas}

Otro conjunto de variables asociadas con el entorno son las denominadas variables específicas. Incluyen los factores que operan en áreas directamente vinculadas con la misión de las organizaciones y el sector económicocomercial donde éstas desarrollan sus funciones. En este caso, una variable clave es la competencia, la cual hace alusión a las relaciones de mercado que se producen entre empresas sociales que ofertan un mismo bien o servicio. La teoría económica le otorga un importante papel como catalizadora de la innovación en las empresas privadas, sin embargo, es importante conocer cómo se comporta esta variable cuando la misión de la organización se orienta a la generación de valor social y no de valor económico.

La evidencia recogida en la literatura muestra que una mayor competencia entre las empresas es determinante en el fomento de la innovación, pues genera incentivos para optimizar los productos y procesos existentes o generar nuevas ideas en función de las preferencias y demandas de los ciudadanos (Kimberly \& Evanisko, 1981, p. 699). De forma genérica se afirma que "la falta de competencia podría llevar a las empresas establecidas a ser menos eficientes y reducir su incentivo de innovar" (OCDE, 2011: 105). Frente a este argumento algunos autores ven en la fragmentación del mercado y la imposibilidad de lograr una competencia perfecta, serias limitaciones al alcance de esta variable (Teece, 1998, p. 138).

\subsubsection{Redes estratégicas}

Al abordar el entorno deben tenerse en cuenta las interacciones de la organización con otros actores y la construcción de mecanismos relacionales de colaboración para la consecución de los objetivos de la organización. El desarrollo de procesos o productos innovadores socialmente, en contextos de alta incertidumbre, requiere de la configuración de modelos de gobernanza en red que propicien la interacción entre diversos actores (públicos, privados o sociales). Esto con la finalidad de propiciar el intercambio de ideas, valores y conocimientos.

Una variable clave para en este apartado es la que se denomina trabajo en red. Describe la capacidad de las organizaciones para establecer alianzas con otros actores de su entorno y definir objetivos comunes que favorezcan el aprendizaje y el intercambio de recursos estratégicos en el marco de un modelo relacional de trabajo.

La posibilidad de conectarse con otros actores y establecer alianzas que sean sostenibles en el tiempo se considera un importante catalizador de la innovación. El intercambio de información con otras organizaciones favorece los procesos de aprendizaje y la mejora continua. En algunos casos, contribuye a reducir los costes 
asociados a la generación de nuevas ideas, cuando se produce un intercambio de conocimientos con otros actores. No se entiende la existencia de organizaciones que funcionen de manera aislada, al margen de la dinámica e interacciones que se produce en su entorno. Esto limitaría su capacidad de aprendizaje y de mejora frente a los desafíos externos e internos que deben afrontar.

\subsection{Modelo de organización}

La teoría de las organizaciones ha generado importantes conceptos a la hora de abordar la manera cómo se articulan los componentes internos de las organizaciones y cómo se orientan al cumplimiento de sus objetivos. A las empresas sociales se le atribuye la adopción de modelos de organización con marcadas diferencias, frente a los modelos comúnmente utilizados por las empresas privadas u otros tipos de organización. De ahí la importancia de valorar el comportamiento de estas variables con respecto a la innovación. Más aún, cuando la evidencia empírica muestra que las variables vinculadas con las características del modelo de organización tienen mayor relevancia como variables explicativas de la innovación que las variables del entorno o las características individuales de los miembros de la organización (Kimberly \& Evanisko, 1981, p. 709).

En este nivel de análisis se incluyen variables relacionadas con el marco estratégico, la estructura organizativa, los recursos, los procedimientos de gestión y la cultura organizativa.

\subsubsection{Marco estratégico}

El marco estratégico está relacionado con la misión y visión de la organización; con la definición de sus objetivos y el diseño de las estrategias a corto, mediano o largo plazo para su consecución. Su importancia radica en que determina la orientación de las organizaciones, la utilización de sus recursos, el aprovechamiento de sus potencialidades y el trabajo de sus miembros. La clave está en qué medida las empresas sociales, manteniendo como epicentro de sus actuaciones la atención de los problemas sociales, fomentan la introducción de cambios significativos en sus productos o servicios. Así como procesos de mejora continua mediante la adopción de nuevos modelos de gobernanza.

Una de las variables clave en este sentido es la orientación estratégica de la organización. Describe el sentido del conjunto de acciones que, de manera planificada, se establecen en la organización para el alcance de sus metas y objetivos. La posibilidad de contar con estrategias que favorezcan el cambio y la creatividad promueven la innovación en la organización, pues crea condiciones positivas para la generación de nuevas ideas. Por el contrario, la existencia de estrategias que no promuevan el cambio y favorezcan el inmovilismo en la organización es una clara barrera para la organización.

\subsubsection{Estructura de la organización}

La estructura organizativa es el marco donde se realizan los procesos internos de la organización e incluye los siguientes componentes: 1. La complejidad, que hace alusión a las divisiones, áreas o departamentos con sus respectivos niveles jerárquicos; 2 . La distribución de la autoridad entre los diferentes componentes de la estructura; 3. La asignación de roles y procedimientos estandarizados; y 4. Las relaciones jerárquicas o interacciones que se producen entre los componentes de la organización (Fernández, 1986, p. 467). Numerosas investigaciones se han centrado en el estudio de la influencia de la estructura de la organización en la innovación, corroborando la existencia de variables estructurales que facilitan e impulsan su desarrollo (Kimberly \& Evanisko, 1981, p. 697).

Dos variables clave son: el tamaño de la organización y el modelo de distribución del poder y la autoridad. El tamaño de la organización tiene que ver con la magnitud de la empresa social medida (de manera estandarizada) en grande, mediana o pequeña, a partir del número de empleados o el volumen de ventas e ingresos. En líneas generales, no existen posiciones claras sobre la relación entre el tamaño de la organización y la innovación. Se considera que las grandes organizaciones tienden a adoptar más innovaciones debido a una mayor disponibilidad de recursos para afrontar nuevos retos, iniciar nuevos proyectos, promover el crecimiento entre sus empleados (Subramanian \& Nilakanta, 1996, p. 635).

Sin embargo, puede argumentarse que las grandes empresas son más burocráticas y menos flexibles e incapaces de adaptarse o cambiar rápidamente frente a los desafíos del entorno y de la propia organización. Otros estudios plantean que las organizaciones pequeñas son más innovadoras porque son más flexibles, tienen mayor capacidad de adaptación y mejorar, y tienen menos dificultades a la hora de promover el cambio (Damanpour, 1996, p. 695).

Una segunda variable clave de la estructura organizativa es la distribución del poder y la autoridad en la organización. Esta variable indica el grado de concentración del poder y la autoridad de acuerdo con el modelo organizativo utilizado. En la literatura se plantea que la descentralización está relacionada con modelos más 
flexibles en la organización favorece la innovación. Se plantea que la distribución del poder en diversas instancias de la organización incrementa la participación de sus miembros, la identificación con sus objetivos y el compromiso para su consecución (Damanpour, 1996, p. 558).

Por otra parte, existe una tradicional asociación de la centralización con la existencia de modelos jerárquicos que se describen como barreras para la innovación. Esto debido a una mayor lentitud en los procesos de toma de decisión y los escasos incentivos para promover nuevas ideas. Para algunos autores la clave no está en la dicotomía entre centralización y descentralización a la hora de analizar su relación con la innovación, sino en la adopción de modelos mixtos que se adecuen a la complejidad de las tareas de la organización (Teece, 1998, p. 142).

\subsubsection{Recursos}

Se entiende por recursos todos los input, tangibles (financieros y físicos) e intangibles (capital intelectual, red de contactos, reputación,... ) que se encuentran a disposición de la organización para el cumplimiento de sus tareas (Grant, 2005, p. 138). La variable clave es la disponibilidad de recursos. En este caso, se acuña el concepto de recursos excedentarios para hacer referencia a la cantidad de recursos de los que dispone la organización, más allá de los mínimamente necesarios para cumplir con sus operaciones y alcanzar sus objetivos prioritarios. El estudio de la disponibilidad de recursos desde una perspectiva principalmente financiera o presupuestaria ha generado posiciones encontradas debido al determinismo económico utilizado a la hora de analizar las organizaciones y la innovación.

La existencia de recursos excedentarios supone que la organización puede afrontar los costos asociados a la adopción de la innovación; absorber los fallos que se produzcan en la experimentación o uso de prototipos y explorar nuevas ideas de acuerdo con las necesidades que haya identificado en su entorno (Rosner, 1968, p. 615).

\subsubsection{Procedimientos de gestión}

Los procedimientos de gestión son las reglas, estándares y acciones que se llevan a cabo de forma rutinaria en la organización para el cumplimiento de las tareas y el alcance de sus objetivos.

La variable clave es la formalización de los procedimientos de gestión. Representa el nivel de énfasis que se da en la organización al cumplimiento de las reglas y la aplicación de estándares en el desarrollo cotidiano de sus actividades. Al vincular esta variable con la innovación, la literatura recoge que una mayor flexibilidad y un menor énfasis en las reglas brindan autonomía a los miembros de la organización y propicia un ambiente favorable para la generación de nuevas ideas.

Por el contrario, la excesiva reglamentación dentro de la organización, la rigidez de los estándares que se hayan establecido y la primacía de su observancia frente a una mayor autonomía de los miembros de la organización, limita considerablemente el desarrollo de procesos innovadores y de mejora continua.

\subsubsection{Cultura organizativa}

La cultura organizativa representa la esencia de la estructura informal de la organización (Teece, 1998, p. 147). Se define como el sistema formado por las creencias básicas, los valores y los comportamientos observados de forma regular en los miembros de la organización, los cuales condicionan sus objetivos, los principios que orientan sus políticas, las relaciones con el entorno y las interacciones que se producen internamente entre sus miembros (Ramió, 1999, p. 193).

Son dos las variables clave que se han seleccionado para el estudio de las empresas sociales. Por un lado, la actitud gerencial la cual puede caracterizarse por su orientación al cambio o resistente a él. La evidencia empírica muestra que actitudes orientadas al cambio generan un clima organizativo propicio para la innovación y permite atender los conflictos que puedan producirse entre las unidades de la organización ante la posibilidad de impulsar cambios de envergadura. De lo contrario, las actitudes resistentes al cambio se plantearían situaciones que bloqueen la dinámica de las organizaciones para generar nuevas ideas e introducir mejoras que propicien la innovación entre sus miembros.

Por otro lado, la segunda variable es la comunicación tanto desde la perspectiva externa como interna. En el primer caso, se aborda la habilidad de la organización para permanecer en contacto e intercambiar información con los agentes de su entorno. Fomenta el intercambio de información y los procesos de aprendizaje que incentivan la creatividad y generación de nuevas ideas dentro de la organización. La posibilidad de que los miembros de la organización mantengan una interacción fluida con agentes externos, permite impulsar procesos de aprendizaje basados en las nuevas tendencias tecnológicas, los procesos novedosos que se estén desarrollando en el entorno o simplemente nuevas formas de hacer las cosas. 
En el caso de la comunicación interna se hace referencia a la forma cómo se extiende y fluye la comunicación entre las los miembros de la organización. La existencia de canales internos que faciliten el intercambio fluido de la información facilita la dispersión de ideas dentro de la organización. Favorece la conexión de diversos puntos de vista con lo que esto supone en cuanto a la generación de oportunidades para impulsar nuevos proyectos e iniciativas de transformación organizativa. Esto enriquece el trabajo y crea un ambiente propicio para el surgimiento de buenas ideas.

\subsection{Recursos humanos}

En la teoría de la organización los recursos humanos se definen como los servicios productivos ofertados por las personas (en lo concerniente a sus habilidades, conocimiento y raciocinio) para desarrollar tareas y tomar decisiones (Grant, 2005, p. 143). Los recursos humanos se abordan a partir de variables personales e institucionales. La primera refleja las características de los miembros de la organización de acuerdo con las tareas y funciones asignadas, y la segunda tiene que ver con las políticas que se aplican en la organización para la gestión del personal.

La variable clave es la cualificación que, entendida como una variable de carácter personal, refleja las habilidades y el conocimiento de los miembros de la organización para el desempeño de sus funciones. Una mayor cualificación entre los miembros de la organización supone a su vez una mayor predisposición para asumir nuevas responsabilidades y asegura la existencia de capacidades idóneas para emprender nuevos proyectos.

\section{CONCLUSIONES}

El debate sobre el significado y el papel de las empresas sociales en la economía se ha dilucidado mediante la adopción de una serie de elementos diferenciadores con respecto a otras organizaciones de carácter empresarial o social. Una de las principales conclusiones del artículo es que la empresa social se distingue de las empresas mercantiles socialmente responsables en dos aspectos fundamentales: su misión y el destino de los beneficios del ejercicio. En cuanto a su misión, la empresa social está focalizada en la atención de los problemas sociales de una población desfavorecida, para lo cual ha de maximizar tanto los procesos de captura como de creación de valor. Las empresas socialmente responsables incorporan en su misión el respeto o la atención de problemas sociales, pero sin ser éste su objetivo principal, su atención suele centrarse en maximizar la captura de valor y en satisfacer, según las condiciones del mercado, la creación de valor.

El destino de los beneficios en una empresa social debe ser, íntegramente, o en su mayoría, la reinversión en su proceso productivo, eliminando o reduciendo a términos poco significativos la remuneración del capital, aspecto distintivo de la empresa mercantil. También encontramos rasgos distintivos en la empresa social frente a la entidad sin ánimo de lucro en su forma de financiación, mientras las últimas dependen de donaciones, la empresa social obtiene sus recursos de una actividad productiva ligada a un objetivo social.

Las empresas sociales se han considerado importantes centro de innovación, debido a la capacidad de sus miembros de generar modelos de negocio que responden a la misión que se han dado (con respecto a la atención de los problemas sociales) y que conjuguen, la generación de valor social y la necesidad de generar ingresos mediante la provisión de bienes y servicios. El estudio de esta dinámica representa una valiosa oportunidad para impulsar procesos de aprendizaje que lleven a la identificación de los factores instituciones que caracterizan esos modelos de negocio, pero que además, hacen de la innovación una realidad.

Las organizaciones públicas tienen en las empresas sociales un importante aliado para la consecución de sus fines. De ahí, que el aprendizaje al que hacíamos mención debe partir del análisis de las buenas prácticas y de la adopción de aquellas iniciativas que siendo exitosas, puedan convertirse en políticas o programas públicos de impacto social. De esta forma, una buena iniciativa podría replicarse en otros contextos, ampliar considerablemente el número de beneficiarios y brindarles la oportunidad a otros actores para participar en su optimización.

Desde una perspectiva organizativa, ese aprendizaje debe considerar los factores que potencian la innovación en las empresas sociales para valorar la posibilidad de impulsar cambios dentro de las propias organizaciones públicas. Por supuesto, teniendo en cuenta los matices que se derivan de su propia naturaleza y del marco normativo-institucional que determina su funcionamiento.

Para ello, el modelo de análisis que se ha propuesto tiene la virtud de ser fácilmente extrapolable a cualquier tipo de organización, pues se sustenta en las premisas básicas de la teoría de la organización, de la teoría de la innovación y del enfoque sistémico. Este modelo se ha estructurado en torno a tres niveles de análisis (macro, meso y micro) que permiten agrupar con mayor agudeza los factores que, de acuerdo con la literatura, son clave en el desarrollo de la innovación. En su mayoría, son factores que generan condiciones favorables a la innovación a medida que catalizan procesos creativos, bajo esquemas abiertos, participativos, inclusivos y deliberativos. 
ILUSTRACIÓN 3. SISTEMA DE VARIABLES (FUENTE: ELABORACIÓN PROPIA).

\begin{tabular}{|c|c|}
\hline Nivel de análisis & Factores \\
\hline \multirow[t]{4}{*}{ Entorno } & 1. Marco normativo e institucional. \\
\hline & 2. Tamaño de la ciudad donde se encuentra implantada la empresa. \\
\hline & 3. Competencia. \\
\hline & 4. Trabajo en red. \\
\hline \multirow[t]{8}{*}{ Organizativo } & 5. Orientación estratégica de la organización. \\
\hline & 6. Tamaño de la organización. \\
\hline & 7. Modelo de distribución del poder y la autoridad. \\
\hline & 8. Disponibilidad de recursos (tangibles e intangibles) \\
\hline & 9. Procedimientos de gestión. \\
\hline & 10. Actitud gerencial. \\
\hline & 11. Comunicación interna. \\
\hline & 12. Comunicación externa. \\
\hline Individual & 13. Cualificación profesional de los recursos humanos. \\
\hline
\end{tabular}

\section{REFERENCIAS BIBLIOGRÁFICAS}

Agafonow, A., 2014. "Value Creation, Value Capture, and Value Devolution: Where Do Social Enterprises Stand?" Administration \& Society, pp.1-23. DOI: 10.1177/0095399714555756.

Arenilla, M. y García-Vegas, R. 2013. "Innovación social. La integración social en la Administración Pública”, Netbiblo, La Coruña.

Argudo Périz, J.L. 2002. "El Tercer Sector y Economía Social, Marco Teórico y Situación Actual”. Acciones e Investigaciones Sociales, pp. 239-263. Disponible en file://C:/Users/Usuario/Downloads/Dialnet-ElTercerSect orYEconomiaSocial-284138.pdf.

Austin, J., Stevenson, H. \& Wei-Skillern, J., 2006. "Social and Commercial Entrepreneurship: Same, Different, or Both?" Entrepreneurship Theory and Practice, 30(1), pp.1-22. DOI: 10.1111/j.1540-6520.2006.00107.x.

Bacq, S. \& Janssen, F., 2011. "The multiple faces of social entrepreneurship: A review of definitional issues based on geographical and thematic criteria". Entrepreneurship \& Regional Development, 23(5-6), pp.373-403. DOI: 10.1080/08985626.2011.577242

Baldridge, J. V., \& Burnham, R. A. (1975). "Organizational Innovation: Individual, Organizational, and Environmental Impacts". Administrative Science Quarterly, 20 (2), 165-176. DOI: 10.2307/2391692.

Borzaga, C. \& Defourny, J., 2004. The emergence of social enterprise, New York: Routledge. DOI: 10.1111/j.14678292.1991.tbo1366.x.

Borzaga, C. \& Galera, G.G., 2012. "The concept and practice of social enterprise: Lessons from the Italian experience". International Review of Social Research, 2(2), pp.95-112. DOI: 10.1515/irsr-2012-0019.

Borzaga, C. \& Tortia, E., 2007. "Social economy organizations in the theory of the firm". In A. Noya \& E. Clarence, eds. The social economy: Building inclusive economies. Paris: OECD Publishing, pp. 23-60. DOI: $10.1787 / 9789264039889$-en.

Buckland H. \& Murillo, D. 2013. Antena de Innovación Social. Vías hacia el cambio Sistémico. Ejemplos y variables para la innovación social. Barcelona: Esade, Universidad Ramón Llull e Instituto de Innovación Social.

Campi, S., Defourny, J. \& Grégiore, O., 2006. "Work integration social enterprises". In M. Nyssens, ed. Social enterprise: At the crossroads of market, public policies and civil society. London: Routledge, pp. 29-49.

Chaves, R. 2007. "La Economía Social en las Políticas Públicas en España”. CIRIEC España. Disponible en http:/l www.empleo.gob.es/es/sec_trabajo/autonomos/economia-soc/NoticiasDoc/NoticiasPortada/ES_politicas publicas_2007.pdf.

CIRIEC-International. 2011. "Social and Solidarity Economy: Our Common Road towards Decent Work". Working Paper In support of the Second edition of the Social and Solidarity Economy Academy, 24-28 October 2011, Montreal, Canada. Disponible en: http://www.ilo.org/wcmsp5/groups/public/--ed_emp/--emp_ent/--coop/ documents/instructionalmaterial/wcms 166301.pdf. 
Comité Económico y Social Europeo. 2012. Dictamen del Comité Económico y Social Europeo sobre “Espíritu empresarial social y las empresas sociales" (Dictamen exploratorio)(2012/C 24/01).

Dacin, P.A., Dacin, M.T. \& Matear, M., 2010. "Social Entrepreneurship: Why We Don't Need a New Theory and How We Move Forward From Here". The Academy of Management Perspectives, 24(3), pp.37-57.

Defourny, J. \& Nyssens, M., 2008. "Social enterprise in Europe: recent trends and developments". Social Enterprise Journal, 4(3), pp.202-228. DOI: 10.1108/17508610810922703.

European Commission, 2013. "Social economy and social entrepreneurship". Social Europe Guide Volume 4, Luxembourg: Publications Office of the European Union. Available at: http://ec.europa.eu/social/main.jsp?ca $\underline{t} \mathrm{ld}=738$ \&langld=en\&publd=7523.

Hansmann, H.B., 2003. "The Role of Trust in Nonprofit Enterprise”. In H. Anheier \& A. Ben-Ner, eds. The Study of the Nonprofit Enterprise. Theories and Approaches. New York: Kluwer Academic/Plenum Publishers, pp. 115-122. DOI: 10.1007/978-1-4615-0131-2_6.

Hoogendoorn, B., Pennings, E. \& Thurik, R., 2010. "What do we know about social entrepreneurship? An analysis of empirical research". International Review of Entrepreneurship, 8(2), pp.1-42.

Hwang, H.; Powell, W.W. 2009. "The Rationalization of Charity: The Influences os Professionalism in the Nonprofit Sector". Administrative Science Quartely. 54: 268-298. DOI: 10.2189/asqu.2009.54.2.268.

Kickul, J. et al., 2012. Social Business Education: An Interview With Nobel Laureate Muhammad Yunus. Academy of Management Learning \& Education, 11(3), pp.453-462. DOI: 10.5465/amle.2011.0500.

Laville, J.L.; Levesque, B; Mendell, M. 2009. "The Social Economuy: Diverse Approaches and Practices in Europe and Canada". En Social Economy: Building Inclusive Economies. OECD. Disponible en http://kwasnicki.prawo. uni.wroc.pl/pliki/The\%20Social\%20Economy\%20Building\%20Inclusive\%20Economies.pdf\#page=157.

Martin, R. \& Osberg, S., 2007. "Social entrepreneurship: The case for definition". Stanford Social Innovation Review, (Spring), pp. 29-39.

Miller, T., Grimes, M., McMullen, F., \& Vogus, T. 2012. "Venturing for others with heart and head: How compassion encourages social entrepreneurship". Academy of Management Review, 37(4), 616-640. DOI: 10.5465/ amr.2010.0456.

Monzón, J.L. 2011. Las Grandes Cifras de la Economía Social en España. Ámbito, Entidades y Cifras Clave. Año 2008. Ciriec España y Observatorio Español de la Economía Social. Disponible en: http://www.divinapastora.com/ fundacion/media/documentos/ciriecgrandesci.pdf.

Monzón, J.L.; CHAVES, R.2012. La Economía Social en la Unión Europea. Informe elaborado para el Comité Económico y Social Europeo por el Centro Internacional de Investigación e Información sobre la Economía Pública, Social y Cooperativa (CIRIEC). Disponible en: http://www.eesc.europa.eu/resources/docs/qe-30-12790-es-c.pdf.

OECD, 2010. SMEs, Entrepreneurship and Innovation, OECD Studies on SMEs and Entrepreneurship, Paris: OECD Publishing.

Ortmann, A. \& Brhlikova, P., 2010. “Theories of Nonprofit Organization, Economic”. In H. K. Anheier \& S. Toepler, eds. International Encyclopedia of Civil Society. New York, NY: Springer US, pp. 1521-1527. DOI: 10.1007/978-0387-93996-4_136.

Peredo, A.M. \& McLean, M., 2006. "Social entrepreneurship: A critical review of the concept". Journal of World Business, 41(1), pp.56-65. DOI:10.1016/j.jwb.2005.10.007.

Sajardo Moreno, A; Chaves Ávila, R. 1999. "El tercer sector como realidad institucional. Delimitación y cuantificación en España y otros países desarrollados”. Ekonomiaz: Revista vasca de economía; 39, pp 82-107.

Santos, F.M., 2012. “A Positive Theory of Social Entrepreneurship”. Journal of Business Ethics, 111(3), pp.335-351. DOI: $10.1007 / \mathrm{s} 10551-012-1413-4$.

Seelos, C. \& Mair, J., 2004. Entrepreneurs in service of the poor: Models for business contributions to sustainable development, Navarra.

Short, J.C., Moss, T.W. \& Lumpkin, G.T., 2009. "Research in social entrepreneurship: past contributions and future opportunities”. Strategic Entrepreneurship Journal, 3(2), pp.161-194. DOI: 10.1002/sej.69.

Social Enterprise UK, 2012. What makes a social enterprise a social enterprise? Available at: http://www. socialenterprise.org.uk/uploads/files/2012/04/what makes a social enterprise a social enterprise april_2012.pdf [Accessed February 16, 2015].

Steinberg, R., 2006. “Economic Theories of Nonprofit Organizations”. In W. W. Powel \& R. Steinberg, eds. The Nonprofit Sector. A Research Handbook. New Haven \& London: Yale University Press, pp. 117-139.

Valentinov, V., 2008. "The Economics of the Non-Distribution Constraint: A Critical Reappraisal". Annals of Public and Cooperative Economics, 79(1), pp.35-52. DOI: 10.1111/j.1467-8292.2007.00351.x.

Yunus, M. \& Weber, K., 2010. Building Social Business. The New Kind of Capitalism that Serves Humanity's Most Pressing Needs, New York: Public Affairs. 
Yunus, M., Moingeon, B. \& Lehmann-Ortega, L., 2010. "Building Social Business Models: Lessons from the Grameen Experience”. Long Range Planning, 43(2-3), pp.308-325.

Zahra, S.A. et al., 2009. "A typology of social entrepreneurs: Motives, search processes and ethical challenges". Journal of Business Venturing, 24(5), pp.519-532.

\section{LEGISLACIÓN}

LEY 44/2007, de 13 de diciembre, para la regulación del régimen de las empresas de inserción.

LEY 5/2011, de 29 de marzo, de Economía Social.

REAL DECRETO 227311985, de 4 de diciembre, por el que se aprueba el Reglamento de los Centros especiales de Empleo definidos en el artículo 42 de la Ley 1311982, de 7 de abriL de integración Social del Minusválido. 
ANEXO. MARCO JURÍDICO DE LA ECONOMÍA SOCIAL EN ESPAÑA

\begin{tabular}{|c|c|c|c|}
\hline \multirow{2}{*}{$\begin{array}{l}\text { Clase de } \\
\text { Entidad }\end{array}$} & \multicolumn{3}{|c|}{ Legislación } \\
\hline & Europea & Estatal & Autonómica \\
\hline $\begin{array}{l}\text { Fomento de } \\
\text { la Economía } \\
\text { Social }\end{array}$ & & $\begin{array}{l}\text { - Ley 5/2011, de } 29 \text { de } \\
\text { marzo, de Economía } \\
\text { Social. } \\
\text { - Decreto 219/2001, de } \\
2 \text { de marzo, regulador } \\
\text { de la organización y } \\
\text { financiamiento del } \\
\text { Consejo para el Fomento } \\
\text { de la Economía Social. }\end{array}$ & $\begin{array}{l}\text { Andalucía: Ley Orgánica } 2 / 2007 \text {, de } 19 \\
\text { de marzo, de reforma del Estatuto de } \\
\text { Autonomía para Andalucía. } \\
\text { Aragón: Ley Orgánica 5/2007 de } 20 \text { de abril } \\
\text { de reforma del estatuto de Autonomía de } \\
\text { Aragón. } \\
\text { Cataluña: Ley Orgánica 6/2006, de } 19 \text { de julio, } \\
\text { de reforma del Estatuto de Autonomía de } \\
\text { Cataluña. } \\
\text { Castilla y León: Ley Orgánica 14/2007, de } 30 \\
\text { de noviembre, de reforma del Estatuto de } \\
\text { Autonomía de Castilla y León. } \\
\text { Valencia: Ley Orgánica } 1 / 2006 \text {, de } 10 \text { de abril, } \\
\text { de Reforma de la Ley Orgánica 5/1982, de } \\
\text { 1 de julio, de Estatuto de Autonomía de la } \\
\text { Comunidad Valenciana. }\end{array}$ \\
\hline Cooperativas & $\begin{array}{l}\text { - Estatuto de } \\
\text { la Sociedad } \\
\text { Cooperativa } \\
\text { Europea } \\
\text { (Reglamento } \\
\text { CE 1435/2003 } \\
\text { del Consejo, } \\
\text { de } 22 \text { de julio } \\
\text { de 2003). } \\
\text { - Directiva } \\
\text { por la que se } \\
\text { completa el } \\
\text { Estatuto de } \\
\text { la Sociedad } \\
\text { Cooperativa } \\
\text { Europea } \\
\text { en lo que } \\
\text { respecta a la } \\
\text { implicación } \\
\text { de los } \\
\text { trabajadores } \\
\text { (Directiva } \\
2003 / 72 / C E \\
\text { del Consejo, } \\
\text { de 22 de julio). }\end{array}$ & $\begin{array}{l}\text { - Ley 3/2011, de } 4 \text { de } \\
\text { marzo, por la que se } \\
\text { regula la Sociedad } \\
\text { Cooperativa Europea } \\
\text { con domicilio en España. } \\
\text { - Ley } 31 / 2006, \text { de } 18 \\
\text { de octubre, sobre } \\
\text { implicación de los } \\
\text { trabajadores en las } \\
\text { sociedades anónimas y } \\
\text { cooperativas europeas. } \\
\text { - Ley } 27 / 1999, \text { de } 16 \text { de } \\
\text { julio, de Cooperativas. } \\
\text { - } \text { Real Decreto } 136 / 2002, \\
\text { de } 1 \text { de febrero, por } \\
\text { el que se aprueba } \\
\text { el Reglamento del } \\
\text { Registro de Sociedades } \\
\text { Cooperativas. }\end{array}$ & $\begin{array}{l}\text { Andalucía: Ley } 2 / 1999 \text {, de } 31 \text { de marzo, de } \\
\text { Cooperativas. } \\
\text { - Ley } 3 / 2002 \text {, de } 16 \text { de diciembre, por la que } \\
\text { se modifica la Ley } 2 / 1999 \text {, de } 31 \text { de marzo, } \\
\text { de Sociedades Cooperativas Andaluzas. } \\
\text { Aragón: Ley } 9 / 1998 \text {, de } 22 \text { de diciembre, } \\
\text { de Cooperativas. Modificada por la Ley } \\
\text { 4/2010, de } 22 \text { de junio. } \\
\text { Asturias: Ley del Principado de Asturias } \\
\text { 4/2010, de } 29 \text { de junio, de Cooperativas. } \\
\text { Baleares: Ley 1/2003, de } 20 \text { de marzo de } \\
\text { Cooperativas modificada por la Ley } \\
\text { 7/2005, de } 21 \text { de junio. } \\
\text { Cataluña: Ley } 18 / 2002 \text {, de } 5 \text { de julio, de } \\
\text { Cooperativas de Cataluña modificada por } \\
\text { Ley 13/2003, de } 13 \text { de junio. } \\
\text { - Decreto 176/1993, de } 13 \text { de julio, de } \\
\text { reglamento de las cooperativas sanitarias } \\
\text { de segundo o ulterior grado. } \\
\text { - Ley 4/1984, de } 24 \text { de febrero, del Instituto } \\
\text { Catalán de Crédito Agrario. } \\
\text { - Ley 6/1998, de } 13 \text { de mayo, de Secciones } \\
\text { de Crédito de las Cooperativas. } \\
\text { Comunidad Castilla-La Mancha: Ley } 20 / 2002 \text {, } \\
\text { de } 14 \text { de noviembre, de Cooperativas de } \\
\text { Castilla-La Mancha. } \\
\text { Comunidad Castilla-León: Ley } 4 / 2002 \text {, de } 11 \\
\text { de abril, de Cooperativas de la Comunidad } \\
\text { de Castilla y León. } \\
\text { Comunidad Madrid: Ley 4/1999, de } 30 \text { de } \\
\text { marzo, de Cooperativas. } \\
\text { Comunidad Valenciana: Ley } 8 / 2003 \text {, de } 24 \text { de } \\
\text { marzo, de Cooperativas de la Comunidad } \\
\text { Valenciana. }\end{array}$ \\
\hline
\end{tabular}




\begin{tabular}{|c|c|c|}
\hline & & 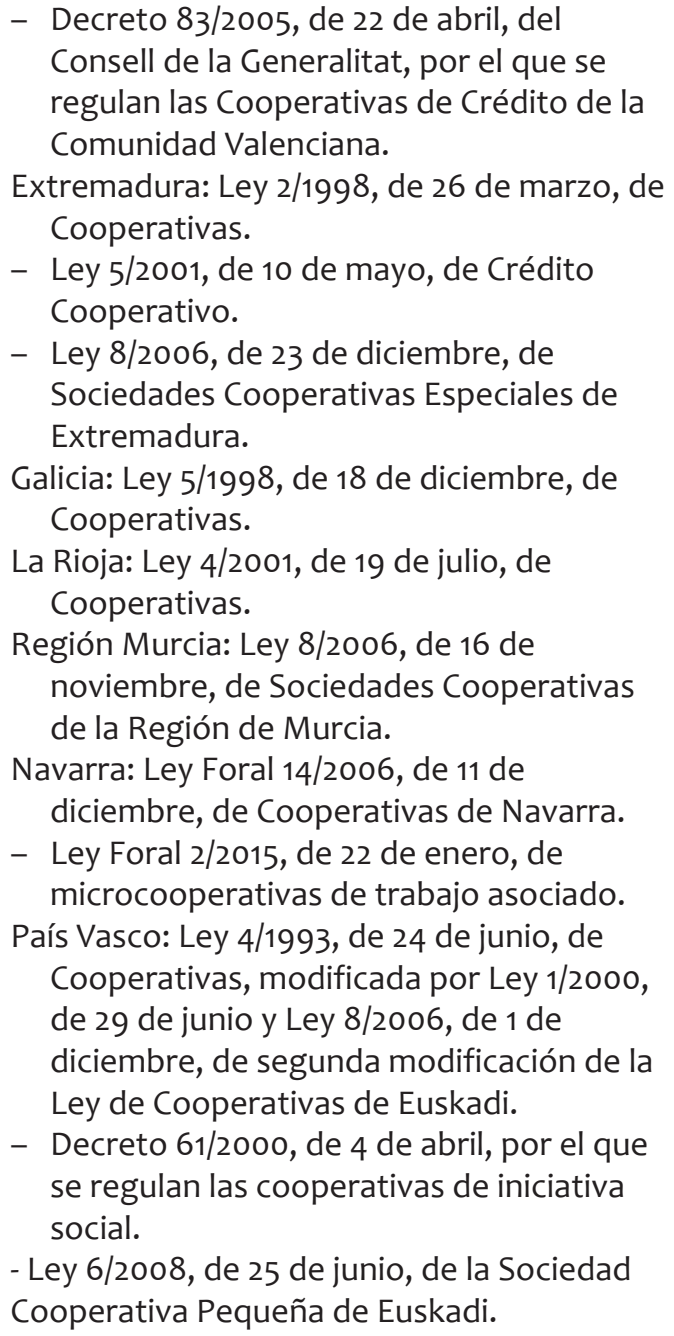 \\
\hline $\begin{array}{l}\text { Mutuas y } \\
\text { Mutualidades } \\
\text { de Previsión } \\
\text { Social }\end{array}$ & $\begin{array}{l}\text { - Real Decreto Legislativo } \\
\text { 6/2004 de } 29 \text { de octubre } \\
\text { por el que se aprueba } \\
\text { el texto refundido de } \\
\text { la ley de ordenación y } \\
\text { supervisión de Seguros } \\
\text { Privados. } \\
\text { - Real Decreto 2486/1998 } \\
\text { de } 20 \text { de noviembre } \\
\text { de Reglamento de la } \\
\text { Ley de Ordenamiento } \\
\text { y Supervisión de los } \\
\text { Seguros Privados. } \\
\text { - Real Decreto 1430/2002, } \\
\text { de } 27 \text { de diciembre, } \\
\text { por el que se aprueba } \\
\text { el Reglamento de } \\
\text { Mutualidades de } \\
\text { Previsión Social. } \\
\text { - Real Decreto 1317/2008, } \\
\text { de } 24 \text { de julio, por el } \\
\text { que se aprueba el Plan } \\
\text { de Contabilidad de las } \\
\text { entidades aseguradoras. }\end{array}$ & $\begin{array}{l}\text { Cataluña: Ley 10/2003, de } 13 \text { de junio, de } \\
\text { Mutualidades de Previsión Social de } \\
\text { Cataluña. } \\
\text { _ } \text { Decreto } 279 / 2003 \text {, de } 4 \text { de noviembre, } \\
\text { de desarrollo de determinados aspectos } \\
\text { de la Ley 10/2003, de } 13 \text { de junio, sobre } \\
\text { mutualidades de previsión social. } \\
\text { Com. Valenciana: Ley 7/2000, de } 29 \text { de mayo, } \\
\text { de Mutualidades de Previsión Social. } \\
\text { Madrid: Ley 9/2000, de } 30 \text { de junio, de } \\
\text { Mutualidades de Previsión Social, } \\
\text { modificada por Ley } 18 / 2000 \text {, de } 27 \text { de } \\
\text { diciembre. } \\
\text { País Vasco: Ley 5/2012, de } 23 \text { de febrero, } \\
\text { sobre Entidades de Previsión Social } \\
\text { Voluntaria del País Vasco. }\end{array}$ \\
\hline
\end{tabular}




\begin{tabular}{|c|c|c|}
\hline Asociaciones & $\begin{array}{l}\text { - Constitución Española } \\
\text { de } 1978 \text {, artículos } 22 \text { y } \\
34 \text { sobre el derecho de } \\
\text { Asociación y Fundación. } \\
\text { - Ley Orgánica 1/2002, de } \\
22 \text { de marzo, reguladora } \\
\text { del Derecho de } \\
\text { Asociación. } \\
\text { - Real Decreto 1497/2003, } \\
\text { de } 28 \text { de noviembre, } \\
\text { por el que se aprueba } \\
\text { el Reglamento del } \\
\text { Registro Nacional de } \\
\text { Asociaciones y de sus } \\
\text { relaciones con los } \\
\text { restantes registros de } \\
\text { asociaciones. } \\
\text { - Real Decreto } 1740 / 2003, \\
\text { de } 19 \text { de diciembre, } \\
\text { sobre procedimientos } \\
\text { relativos a asociaciones } \\
\text { de utilidad pública. }\end{array}$ & $\begin{array}{l}\text { Andalucía: Ley 4/2006 de } 23 \text { de junio de } \\
\text { Asociaciones de Andalucía. } \\
\text { Andalucía: Ley 4/2006 de } 23 \text { de junio de } \\
\text { Asociaciones de Andalucía. } \\
\text { Canarias: Ley 4/2003, de } 28 \text { de febrero, de } \\
\text { Asociaciones de Canarias. } \\
\text { Cataluña: Ley } 7 / 1997 \text {, de } 18 \text { de junio de } \\
\text { Asociaciones de Cataluña. } \\
\text { Com. Valenciana: Ley 14/2008, de } 18 \text { de } \\
\text { noviembre de } 2008 \text {, de la Generalitat, de } \\
\text { Asociaciones de la Comunitat Valenciana. } \\
\text { País Vasco: Ley } 7 / 2007 \text { de } 22 \text { de junio, de } \\
\text { Asociaciones de Euskadi. }\end{array}$ \\
\hline Fundaciones & $\begin{array}{l}\text { - } \text { Ley } 50 / 2002 \text {, de } 26 \\
\text { de diciembre, de } \\
\text { Fundaciones. } \\
\text { - } \text { Real Decreto } 1337 / 2005 \text {, } \\
\text { de } 11 \text { de noviembre, } \\
\text { por el que se aprueba } \\
\text { el Reglamento de } \\
\text { fundaciones de } \\
\text { competencia estatal. } \\
\text { - Ley } 49 / 2002 \text {, de } 23 \text { de } \\
\text { diciembre, de régimen } \\
\text { fiscal de las entidades } \\
\text { sin fines lucrativos y de } \\
\text { los incentivos fiscales al } \\
\text { mecenazgo. } \\
\text { - Real Decreto } 1270 / 2003 \\
\text { de } 10 \text { de octubre por } \\
\text { el que se aprueba el } \\
\text { Reglamento para la } \\
\text { aplicación del régimen } \\
\text { fiscal de las entidades } \\
\text { sin fines lucrativos y de } \\
\text { los incentivos fiscales al } \\
\text { mecenazgo. }\end{array}$ & $\begin{array}{l}\text { Andalucía: Ley 10/2005, de } 31 \text { de mayo, de } \\
\text { Fundaciones. } \\
\text { Aragón: Decreto } 276 / 1995 \text {, de } 19 \text { de } \\
\text { diciembre, de la Diputación General } \\
\text { de Aragón, por el que se regulan las } \\
\text { competencias en materia de Fundaciones } \\
\text { y se crea el Registro de Fundaciones. } \\
\text { Asturias: Decreto 34/1998, de } 18 \text { de junio, } \\
\text { por el que se crea y regula el Registro } \\
\text { de Fundaciones Docentes y Culturales } \\
\text { de Interés General del Principado de } \\
\text { Asturias, modificado por Decreto } 12 / 2000 . \\
\text { Baleares: Decreto } 61 / 2007 \text {, de } 18 \text { de mayo, } \\
\text { de Regulación del Registro Único de } \\
\text { Fundaciones de la Comunidad Autónoma } \\
\text { de las Illes Balears y de Organización del } \\
\text { Ejercicio del Protectorado. } \\
\text { Canarias: Ley } 2 / 1998, \text { de } 6 \text { de abril, de } \\
\text { Fundaciones. } \\
\text { Castilla y León: Ley 13/2002, de } 15 \text { de julio, de } \\
\text { Fundaciones. } \\
\text { Cataluña: Ley } 21 / 2014, \text { de } 29 \text { de diciembre, } \\
\text { del protectorado de las fundaciones } \\
\text { y de verificación de la actividad de las } \\
\text { asociaciones declaradas de utilidad } \\
\text { pública. } \\
\text { Galicia: Ley 12/2006, de } 1 \text { de diciembre, de } \\
\text { fundaciones de interés gallego. } \\
\text { La Rioja: Ley } 1 / 2007, \text { de } 12 \text { de febrero, de } \\
\text { Fundaciones de la Comunidad Autónoma } \\
\text { de La Rioja. } \\
\text { Madrid: Ley 1/1998, de } 2 \text { de marzo, de } \\
\text { Fundaciones, modificada por Ley } 24 / 1999 \text {, } \\
\text { de } 27 \text { de diciembre. }\end{array}$ \\
\hline
\end{tabular}




\begin{tabular}{|c|c|c|}
\hline & $\begin{array}{l}\text { - Real Decreto 1491/2011 } \\
\text { 1491/2011, de } 24 \text { de } \\
\text { octubre, por el que se } \\
\text { aprueban las normas } \\
\text { de adaptación del Plan } \\
\text { General de Contabilidad } \\
\text { a las entidades sin fines } \\
\text { lucrativos y el modelo } \\
\text { de plan de actuación de } \\
\text { las entidades sin fines } \\
\text { lucrativos. }\end{array}$ & $\begin{array}{l}\text { Navarra: Ley Foral 10/1996, de } 2 \text { de julio, } \\
\text { reguladora del régimen tributario de } \\
\text { las fundaciones y de las actividades de } \\
\text { patrocinio. } \\
\text { País Vasco: Ley } 12 / 1994 \text {, de } 17 \text { de junio, de } \\
\text { Fundaciones. } \\
\text { Valencia: Ley } 8 / 1998 \text {, de } 9 \text { de diciembre, de } \\
\text { Fundaciones. }\end{array}$ \\
\hline $\begin{array}{l}\text { Sociedades } \\
\text { Laborales y } \\
\text { SAT }\end{array}$ & $\begin{array}{l}\text { - Ley } 4 / 1997, \text { de } 24 \text { de } \\
\text { marzo, de Sociedades } \\
\text { Laborales. } \\
\text { - } \text { Real Decreto } 2114 / 1998, \\
\text { de } 2 \text { de octubre, } \\
\text { regulador del Registro } \\
\text { Administrativo de } \\
\text { Sociedades Laborales. }\end{array}$ & \\
\hline $\begin{array}{l}\text { Empresas } \\
\text { de Inserción } \\
\text { Social }\end{array}$ & $\begin{array}{l}\text { - Ley 44/2007 del } 13 \text { de } \\
\text { diciembre sobre las } \\
\text { Empresas de Inserción. }\end{array}$ & 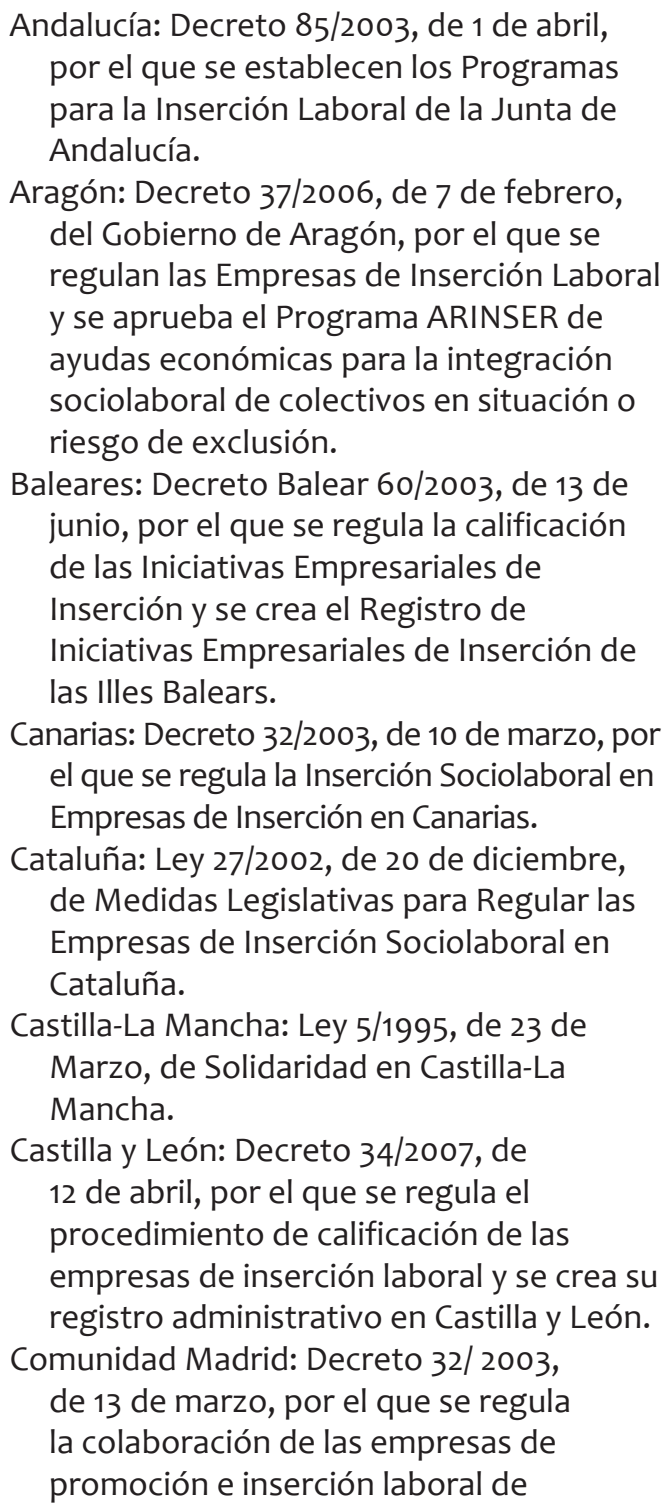 \\
\hline
\end{tabular}




\begin{tabular}{|c|c|c|}
\hline & & $\begin{array}{l}\text { personas en situación de exclusión } \\
\text { social con la Comunidad de Madrid y se } \\
\text { establecen medidas de fomento de su } \\
\text { actividad. } \\
\text { Comunidad Valenciana: Ley } 1 / \text { /2007, de } 5 \\
\text { de febrero, de la Generalitat, por la que } \\
\text { se regulan las Empresas de Inserción } \\
\text { para fomentar la inclusión social en la } \\
\text { Comunitat Valenciana. } \\
\text { Legislación autonómica Galicia: Ley 10/2013, de } 27 \\
\text { de noviembre, de inclusión social de Galicia. } \\
\text { La Rioja: Ley } 7 / 2003 \text {, de } 26 \text { de marzo, de } \\
\text { Inserción Sociolaboral de la Rioja. } \\
\text { Región de Murcia: Orden de } 20 \text { de junio } \\
\text { de } 2007, \text { de la Presidenta del Servicio } \\
\text { Regional de Empleo y Formación, por la } \\
\text { que se aprueban las bases reguladoras de } \\
\text { los programas de subvenciones para el } \\
\text { fomento de las empresas de inserción de } \\
\text { la Región de Murcia. } \\
\text { Navarra: Decreto Foral } 130 / 1999 \text {, de } 26 \text { de } \\
\text { abril, por el que se regulan las ayudas } \\
\text { económicas para el desarrollo de los } \\
\text { programas de incorporación socio-laboral } \\
\text { destinados a personas en situación de } \\
\text { exclusión social de Navarra. } \\
\text { País Vasco: Decreto } 182 / 2008 \text {, de } 11 \text { de } \\
\text { noviembre, por el que se regula la } \\
\text { calificación de empresas de inserción, se } \\
\text { establece el procedimiento de acceso a } \\
\text { las mismas y su registro de Euskadi. }\end{array}$ \\
\hline $\begin{array}{l}\text { Centros } \\
\text { Especiales de } \\
\text { Empleo }\end{array}$ & $\begin{array}{l}\text { - RD } 2273 / 1985 \text {, de } 4 \text { de } \\
\text { diciembre, por el que se } \\
\text { aprueba el reglamento } \\
\text { de los centros especiales } \\
\text { de empleo definidos en } \\
\text { el artículo } 42 \text { de la ley } \\
\text { 13/1982, de } 7 \text { de abril, de } \\
\text { integración social del } \\
\text { minusválido. } \\
\text { - RD 427/1999 de } 12 \text { de } \\
\text { marzo por el que se } \\
\text { modifica el RD } 1368 / 1985 \\
\text { de } 17 \text { de julio. Regula } \\
\text { la relación laboral de } \\
\text { carácter especial de } \\
\text { los minusválidos que } \\
\text { trabajen en Centros } \\
\text { Especiales de Empleo. } \\
\text { - RD Legislativo } 1 / 2013, \\
\text { Texto Refundido de la } \\
\text { Ley General de derechos } \\
\text { de las personas con } \\
\text { discapacidad y su } \\
\text { inclusión social. }\end{array}$ & $\begin{array}{l}\text { Andalucía: Orden de } 10 \text { de octubre del 2011, } \\
\text { por la que se modifica la Orden de } 20 \text { de } \\
\text { octubre del 2010, por la que se regula } \\
\text { el procedimiento de de calificación e } \\
\text { inscripción de los Centros Especiales } \\
\text { de Empleo y se establecen las bases } \\
\text { reguladoras de la concesión de incentivos } \\
\text { para Centros Especiales de Empleo } \\
\text { regulados en el Decreto 149/2005, de } 14 \\
\text { de junio. }\end{array}$ \\
\hline
\end{tabular}

Fuente: Actualizado y ampliado sobre Monzón (2011). 